\title{
Evaluation of Partnership Working in Cities in Phase IV of the WHO Healthy Cities Network
}

\author{
Alistair Lipp, Tim Winters, and Evelyne de Leeuw
}

\begin{abstract}
An intersectoral partnership for health improvement is a requirement of the WHO European Healthy Cities Network of municipalities. A review was undertaken in 59 cities based on responses to a structured questionnaire covering phase IV of the network (2003-2008). Cities usually combined formal and informal working partnerships in a pattern seen in previous phases. However, these encompassed more sectors than previously and achieved greater degrees of collaborative planning and implementation. Additional WHO technical support and networking in phase IV significantly enhanced collaboration with the urban planning sector. Critical success factors were high-level political commitment and a well-organized Healthy City office. Partnerships remain a successful component of Healthy City working. The core principles, purpose and intellectual rationale for intersectoral partnerships remain valid and fit for purpose. This applied to long-established phase III cities as well as newcomers to phase IV. The network, and in particular the WHO brand, is well regarded and encourages political and organizational engagement and is a source of support and technical expertise. A key challenge is to apply a more rigorous analytical framework and theory-informed approach to reviewing partnership and collaboration parameters.
\end{abstract}

KEYWORDS Healthy cities, Health partnerships, Intersectoral partnerships

\section{INTRODUCTION}

That health is made outside the 'health services sector' is a key tenet of the Healthy Cities movement. In her review of policy literature leading eventually to the inclusion of 'Healthy Public Policy' in the Ottawa Charter, Nancy Milio ${ }^{1}$ demonstrated how population health is influenced by the public policy of virtually every sector. Her analysis of nearly 2,000 public policies highlighted the wide range of political decisions which change health outcomes-whether for agriculture, economics, social assistance, transportation, or any other sector.

In the foundational work for what is now a global movement, Hancock and $\mathrm{Duhl}^{2}$ state that "City governments are often the closest level of government to people that have the mandate, the authority and the administrative resources needed to bring together the wide variety of skills and resources needed for at multi-sectoral approach to health" (p. 15). Municipal governments were identified by the WHO Regional Office for Europe as lead partners at the launch of its European Healthy Cities

Lipp and Winters are with the Great Yarmouth and Waveney Primary Care Trust, Beccles, UK; de Leeuw is with the Faculty of Health, Deakin University, Geelong, Australia.

Correspondence: Evelyne de Leeuw, Faculty of Health, Deakin University, Geelong, Australia. (E-mail: evelyne.deleeuw@deakin.edu.au) 
Network (WHO-EHCN) in $1987^{3}$, and for phase IV (2003-2008) an intersectoral partnership remained a requirement for membership of the network. ${ }^{4}$

Critical literature reviews of partnerships for public health help frame our evaluation. First, Healthy Cities' partnerships are voluntary and should be distinguished from new models of European city governance which typically include mandatory partnerships. ${ }^{5}$ Second, our focus is on process rather than outcome, ${ }^{6}$ assuming that facilitative structures, collaborative working and healthy public policy are preconditions for better population health. ${ }^{7}$ Understood as 'mutual engagement', Healthy City partnerships can be described on the continuum networkingcoordinating-cooperating-collaborating ${ }^{8}$ or isolation-encounter-communicationcollaboration-integration. ${ }^{9}$ Successful partnerships tend to be sustainable in terms of resources and time horizon when they move towards the 'right' of these spectra.

Partnership work is a complex affair. A substantial body of literature exists on its conceptual, theoretical, methodological, and empirical foundations. As suggested above, there are considerable differences in the intensities and degrees of partner connections, ranging between isolation, or the occasional encounter and the full (and reciprocal) integration of work, and governance systems. Jones and Barry ${ }^{10}$ demonstrate that the evidence of effectiveness of partnerships is a contested research area and claim that synergy measures would be an appropriate proxy for effectiveness. An argument that they fail to make, however, deals with the diversity and scale of partnerships. A health promotion or Healthy City partnership is not necessarily similar to other forms of collaboration such as the coalition: in the arena of (political) coalitions, the theoretical 'rules of the game' are much clearer. Very briefly, in a political coalition, one needs to assemble a combined power base on a specific issue between the smallest number of stakeholders possible. ${ }^{11}$ For example, if a coalition between two political parties would yield an ordinary majority of votes, there is no reason to invite a third party to join the coalition. Most partnerships in the health field, however, are not governed by such simple and straightforward rules of engagement.

The reasons for the added complexities of health promotion and Healthy Cities partnerships can predominantly be found in the multifaceted dynamic flux of community health issues. As Goumans ${ }^{12}$ has shown, mapping the domain of health promotion presents considerable challenges: in some local government areas, it includes the education sector, but excludes the commercial energy players, and in others, the police force finds itself at the centre of the domain with health actors at the periphery. With shifts in national, regional, and community agendas, however, the prominence and centrality of actors may change, and thus would the nature of the partnership. Mapping roles, relations and objectives of (potential) partnership participants is critical for its effective interaction with policy development for Healthy Cities. ${ }^{13}$

A strong rhetorical flavour has always been part of the partnership argument. The fact that the social model of health hinges on the idea that virtually any social sector impacts on health has resulted in strong calls for collaboration and partnership, from pronouncements on primary health care at Alma Ata to a continued emphasis on them throughout the series of Global Health Promotion conferences. ${ }^{14}$ From these statements, it might appear that the health partnership should be a goal in itself. Most stakeholders in health promotion partnerships, indeed, acknowledge that the partnership is both a process and a product ${ }^{10}$ : it is hard work to build and maintain the partnership and to have it deliver its intended outcomes. Hueben and De Leeuw ${ }^{15}$ (based on Gray ${ }^{16}$ ) describe the conditions under which partnership work is important and likely: 
- When stakeholders are challenged by a multitude of challenging issues;

- When these problems are perceived to be exceeding the problem-solving capacities of individual, autonomous sectoral stakeholders;

- When traditional routines of problem-solving no longer yield results;

- When competing agencies or units start creating unanticipated and dissonant consequences of actions that might still be considered 'routine' responses; and

- When stakeholder agencies or units recognise mutual and often reciprocal temporal and causal interdependencies.

Based on these drivers of seeking partnership arrangements, it is no surprise that a range of multidisciplinary approaches have focused on various parameters of successful partnering.

El Ansari et al. ${ }^{17}$ as well as Jones and Barry ${ }^{10}$ list the following aspects as being critical for successful health promotion (and, by inference, Healthy City) partnerships. The rhetoric around constructive and empowered engagement of end-user communities has long been considered of more value than evidence-based. Zahner ${ }^{18}$ shows that diverse representation including communities would yield effective partnerships. Boundary-spanning skills are required components of successful partnership development and maintenance (e.g. Skok ${ }^{19}$ ). Those skills, particularly when located within an integrative and learning leadership style, would successfully drive collaboration and sharing. Similarities in organizational culture will enhance partnership probabilities, but differences need to be resolved and are often the main reason for partnerships to terminate. This leads to the necessity of building and sustaining both trust and trustworthiness among (potential) partners. Naturally, a willingness to acknowledge partners' power bases and recognising the need to devolve power to the partnership is an essential precondition for a working partnership. A final component for partnership effectiveness mentioned in the literature is that of transparent communication and management.

The evaluation report has taken a pragmatic position. Although the conceptual factors listed above have been highlighted by our respondents, we did not explicitly seek them; our interest was focused on the question whether European Healthy City partnerships are engaged in processes that would lead them towards more integrated and sustained collaboration for city health between phases III and IV.

\section{METHODOLOGY}

This article on partnerships is part of a wider evaluation of phase IV of the WHO European Healthy Cities Network. It builds on an earlier evaluation of phase III. ${ }^{20}$ For both evaluations, the principal research instrument was a questionnaire sent to member cities of the Network-71 in phase III and 79 in phase IV. For this analysis, data were extracted from responses by 59 cities in 23 countries near the end of phase IV in 2008.

Since there is compelling evidence that health outcomes are determined by the activities of many sectors, it was considered legitimate and practical to focus on the processes of engagement and collaboration by sector partners at a city level. Assessments of the process were subjective-coordinators were asked to complete the questionnaire on behalf of and with the knowledge of the partnership and the responses were ratified by a political representative of the Healthy Cities steering group. Cities were asked to respond with integrity, but because of a human tendency 
to justify local effort, their responses may be biased towards achievements: the 20 non-responding cities may hide underperformance.

Eight questions on partnerships in phase IV evolved from the previous questionnaire used to evaluate phase III. A compromise was sought between (1) identical questions which would facilitate comparison between the phases and (2) a need to refine questions which had lacked clarity and led to imprecise responses. Though four questions on partnership structures were retained, four additional questions sought responses on the developmental spectrum referred to in the Introduction. Ordinal scaling was introduced to indicate both the level of engagement with key sectors and cities' assessment of the achievement of their formal partnership. A further two questions elicited free text responses on lessons learnt and facilitative factors or obstacles to intersectoral work.

Free text answers were studied for common themes, and quotes have been abstracted to illustrate these. Median scores were calculated from an ordinal scale applied to the responses on engagement, as described in Findings: sectors and phases were compared. To provide context and explore differences which may have their origins in different political and economic systems, results are shown according to the city's location in WHO epidemiological sub-regions. There are three in Europe: EUR A, with very low child, very low adult mortality (e.g. many Western European countries); EUR B, with low child, low adult mortality (e.g. many Eastern European countries); and EUR C, with low child, high adult mortality (e.g. Baltic states, Hungary, Belarus, Ukraine, Russian Federation).

\section{FINDINGS}

Of the 79 Healthy Cities, 57 (72\%) answered at least one of the eight questions on partnership. Response rates varied between 52 and 56 cities answering each question.

\section{Question 2.1 asked: "Please assess the level of engagement of Healthy Cities with partners from key sectors?"}

Fifty-six cities responded, ranking their level of engagement with eight defined sectors (and any 'other') onto which a five-point ordinal scale was applied ranging from (1) 'no contact' through (2) 'share information' (3) 'agreement to collaborate', (4) 'collaboration has resulted in agreed plans/strategies', to (5) 'implementation of collaborative plans, projects or programmes'. The most collaborative partnerships (Figure 1) were with the health $(76 \%$ of cities) and social service $(69 \%)$ sectors followed by the education $(56 \%)$ and voluntary sectors $(46 \%)$ and then urban planning $(42 \%)$, a new developmental topic in phase IV. Partnerships were the least collaborative in the environmental protection $(36 \%)$ transport $(28 \%)$ and economic development sectors $(13 \%)$.

City partnerships with the health sector were equally well developed in EUR A and EUR B $+\mathrm{C}$ countries (Figures 2 and 3). Cities in EUR B+C countries were more likely than those in EUR A countries to have well-developed partnerships with the education and social services sectors and, to a lesser extent, the voluntary and economic development sectors. Cities in EUR A countries were more likely than cities in EUR $\mathrm{B}+\mathrm{C}$ countries to have well-developed partnerships with the urban planning, environmental protection, transport and 'other' sectors (the small numbers of EUR $B+C$ cities meant that these differences did not reach statistical significance). 


\begin{tabular}{|c|c|c|c|c|c|c|c|c|c|}
\hline \multirow{10}{*}{$\begin{array}{r}100 \% \\
90 \% \\
80 \% \\
70 \% \\
60 \% \\
50 \% \\
40 \% \\
30 \% \\
20 \% \\
10 \% \\
0 \%\end{array}$} & & & & & & & & & \\
\hline & & & & & & & & & \\
\hline & & & & & & & & & \\
\hline & & & & & & & & & \\
\hline & & & & & & & & & \\
\hline & & & & & & & & & \\
\hline & & & & & & & & & \\
\hline & & & & & & & & & \\
\hline & & & & & & & & & \\
\hline & $\mathrm{Ed}$ & VS & ED & UP & EP & $\mathrm{T}$ & HS & SS & $\mathrm{O}$ \\
\hline No contact & $0 \%$ & $0 \%$ & $11 \%$ & $0 \%$ & $2 \%$ & $7 \%$ & $0 \%$ & $0 \%$ & $7 \%$ \\
\hline Share information & $7 \%$ & $11 \%$ & $23 \%$ & $4 \%$ & $9 \%$ & $17 \%$ & $0 \%$ & $2 \%$ & $11 \%$ \\
\hline Agreement to collaborate & $18 \%$ & $19 \%$ & $32 \%$ & $20 \%$ & $20 \%$ & $24 \%$ & $9 \%$ & $11 \%$ & $7 \%$ \\
\hline $\begin{array}{l}\text { Collaboration has resulted in } \\
\text { agreed plans/strategies }\end{array}$ & $21 \%$ & $24 \%$ & $21 \%$ & $35 \%$ & $33 \%$ & $24 \%$ & $15 \%$ & $18 \%$ & $30 \%$ \\
\hline $\begin{array}{l}\text { Implementation of collaborative } \\
\text { plans, projects or programmes }\end{array}$ & $54 \%$ & $46 \%$ & $13 \%$ & $42 \%$ & $36 \%$ & $28 \%$ & $76 \%$ & $69 \%$ & $44 \%$ \\
\hline
\end{tabular}

Sectors involved in the partnership: Ed = Education; VS = Voluntary sector; ED = Economic development; UP = Urban planning; $T=$ Transport; HS = Health services; $\mathrm{SS}=$ Social services; $\mathrm{O}=$ Other.

FIGURE 1. Extent of partnership working in phase IV.

Using the distribution of scores, the sectors were ranked as follows (median score in parentheses): health service sector (5), social services (5), education (5), urban planning (4), voluntary sector (4), environmental protection (4), transport (4), and economic development (3). The 31 cities participating in both phase III and phase IV increased the extent of partnership working in all sectors (Figure 4). The largest increase occurred with the urban planning sector $(3 \%$ rising to $42 \%$, chi square $p<0.003$ ), which was a specific focus of phase IV (Figure 5), and the smallest increase occurred in environmental protection.

\begin{tabular}{|c|c|c|c|c|c|c|c|c|c|c|}
\hline \multirow{11}{*}{ 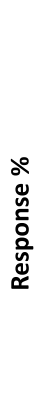 } & \multicolumn{10}{|l|}{$100 \%$} \\
\hline & \multicolumn{10}{|l|}{$90 \%$} \\
\hline & \multicolumn{10}{|l|}{$80 \%$} \\
\hline & \multicolumn{10}{|l|}{$70 \%$} \\
\hline & \multicolumn{10}{|l|}{$60 \%$} \\
\hline & \multicolumn{10}{|l|}{$50 \%$} \\
\hline & \multicolumn{10}{|l|}{$40 \%$} \\
\hline & \multicolumn{10}{|l|}{$30 \%$} \\
\hline & \multicolumn{10}{|l|}{$20 \%$} \\
\hline & \multicolumn{10}{|l|}{$10 \%$} \\
\hline & $0 \%$ & Ed & VS & ED & UP & EP & T & HS & SS & 0 \\
\hline \multicolumn{2}{|c|}{ No contact } & $0 \%$ & $0 \%$ & $16 \%$ & $0 \%$ & $3 \%$ & $8 \%$ & $0 \%$ & $0 \%$ & $5 \%$ \\
\hline \multicolumn{2}{|c|}{ Share information } & $7 \%$ & $10 \%$ & $18 \%$ & $3 \%$ & $10 \%$ & $10 \%$ & $0 \%$ & $3 \%$ & $0 \%$ \\
\hline \multicolumn{2}{|c|}{ Agreement to collaborate } & $20 \%$ & $18 \%$ & $32 \%$ & $15 \%$ & $20 \%$ & $26 \%$ & $5 \%$ & $13 \%$ & $0 \%$ \\
\hline \multicolumn{2}{|c|}{$\begin{array}{c}\text { Collaboration has resulted in } \\
\text { agreed plans/strategies }\end{array}$} & $27 \%$ & $28 \%$ & $24 \%$ & $35 \%$ & $25 \%$ & $26 \%$ & $18 \%$ & $20 \%$ & $32 \%$ \\
\hline \multicolumn{2}{|c|}{$\begin{array}{l}\text { Implementation of collaborative } \\
\text { plans, projects or programmes }\end{array}$} & $46 \%$ & $44 \%$ & $11 \%$ & $48 \%$ & $43 \%$ & $31 \%$ & $78 \%$ & $65 \%$ & $63 \%$ \\
\hline
\end{tabular}

Sectors involved in the partnership: Ed = Education; VS = Voluntary sector; ED = Economic development; UP = Urban planning; $\mathrm{T}=$ Transport; $\mathrm{HS}=$ Health services; $\mathrm{SS}=$ Social services; $\mathrm{O}=$ Other .

FIGURE 2. Extent of partnership working - "EUR A" countries. 


\begin{tabular}{|c|c|c|c|c|c|c|c|c|c|c|}
\hline & \multirow{11}{*}{$\begin{array}{r}30 \% \\
20 \% \\
10 \% \\
0 \%\end{array}$} & & & & & & & & & \\
\hline & & & & & & & & & & \\
\hline & & & & & & & & & & \\
\hline & & & & & & & & & & \\
\hline & & & & & & & & & & \\
\hline & & & & & & & & & & \\
\hline & & & & & & & & & & \\
\hline & & & & & & & & & & \\
\hline & & & & & & & & & & \\
\hline & & & & & & & & & & \\
\hline & & $\mathrm{Ed}$ & VS & ED & UP & EP & $\mathrm{T}$ & HS & SS & 0 \\
\hline \multicolumn{2}{|r|}{ No contact } & $0 \%$ & $0 \%$ & $0 \%$ & $0 \%$ & $0 \%$ & $7 \%$ & $0 \%$ & $0 \%$ & $13 \%$ \\
\hline \multicolumn{2}{|r|}{ Share information } & $7 \%$ & $13 \%$ & $33 \%$ & $7 \%$ & $7 \%$ & $33 \%$ & $0 \%$ & $0 \%$ & $38 \%$ \\
\hline \multicolumn{2}{|r|}{ Agreement to collaborate } & $13 \%$ & $20 \%$ & $33 \%$ & $33 \%$ & $20 \%$ & $20 \%$ & $20 \%$ & $7 \%$ & $25 \%$ \\
\hline \multicolumn{2}{|r|}{$\begin{array}{c}\text { Collaboration has resulted in } \\
\text { agreed plans/strategies }\end{array}$} & $7 \%$ & $13 \%$ & $13 \%$ & $33 \%$ & $53 \%$ & $20 \%$ & $7 \%$ & $13 \%$ & $25 \%$ \\
\hline \multicolumn{2}{|r|}{$\begin{array}{c}\text { Implementation of collaborative } \\
\text { plans, projects or programmes }\end{array}$} & $73 \%$ & $53 \%$ & $20 \%$ & $27 \%$ & $20 \%$ & $20 \%$ & $73 \%$ & $80 \%$ & $0 \%$ \\
\hline
\end{tabular}

Sectors involved in the partnership: Ed = Education; VS = Voluntary sector; ED = Economic development; UP = Urban planning; $\mathrm{T}=$ Transport; $\mathrm{HS}=$ Health services; $\mathrm{SS}=$ Social services; $\mathrm{O}=$ Other.

FIGURE 3. Extent of partnership working - "EUR B +C" countries.

Question 2.2: How would you assess the level of achievement of your main/formal bealthy city partnership?

Fifty-two cities responded. Almost all cities (98\%) reported a 'functioning' partnership structure, and partners 'agreed to work together' (94\%). However, 16\% had yet to 'agree collaborative plans or strategies' and $12 \%$ had not 'implemented any collaborative projects or programmes'. Cities struggling to achieve the most basic levels of partnership working were in the WHO group of 'EUR B + C' countrieslargely former Soviet bloc and Eastern European countries $(p<0.08$, Figure 6).

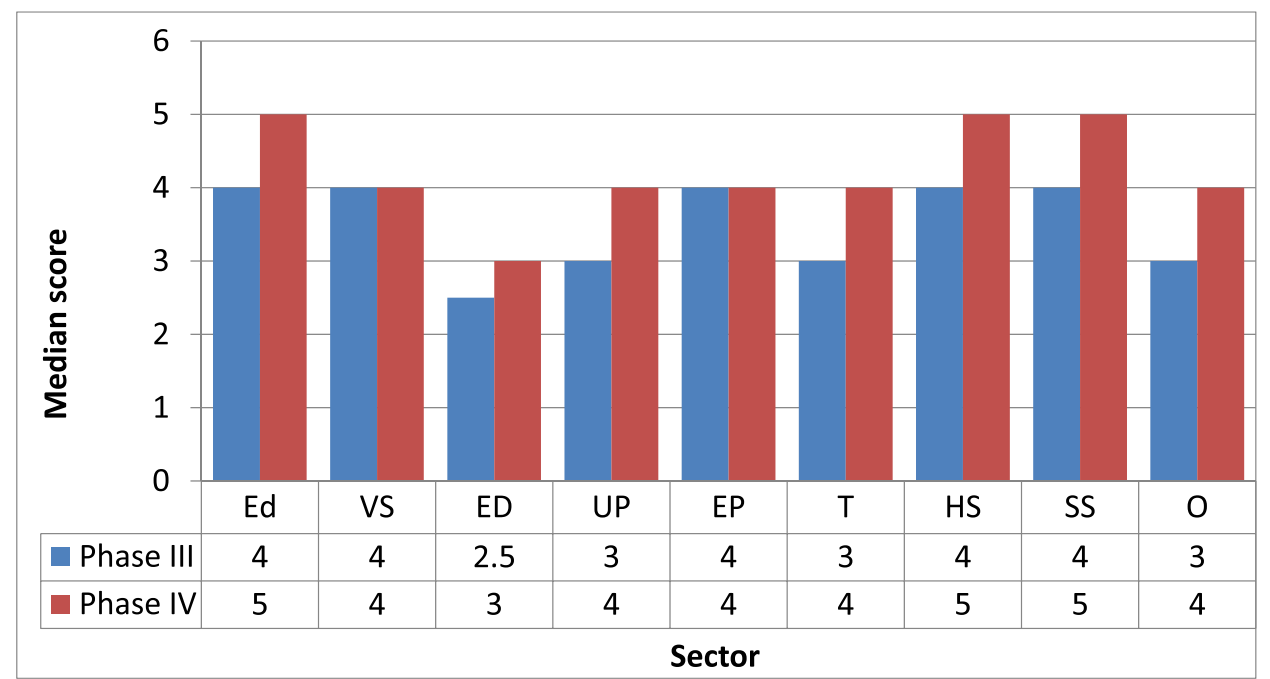

Sectors involved in the partnership: Ed = Education; VS = Voluntary sector; ED = Economic development; UP = Urban planning; $\mathrm{T}=$ Transport; $\mathrm{HS}=$ Health services; $\mathrm{SS}=$ Social services; O = Other.

FIGURE 4. Median score for partnership development changes between phase III and IV. 


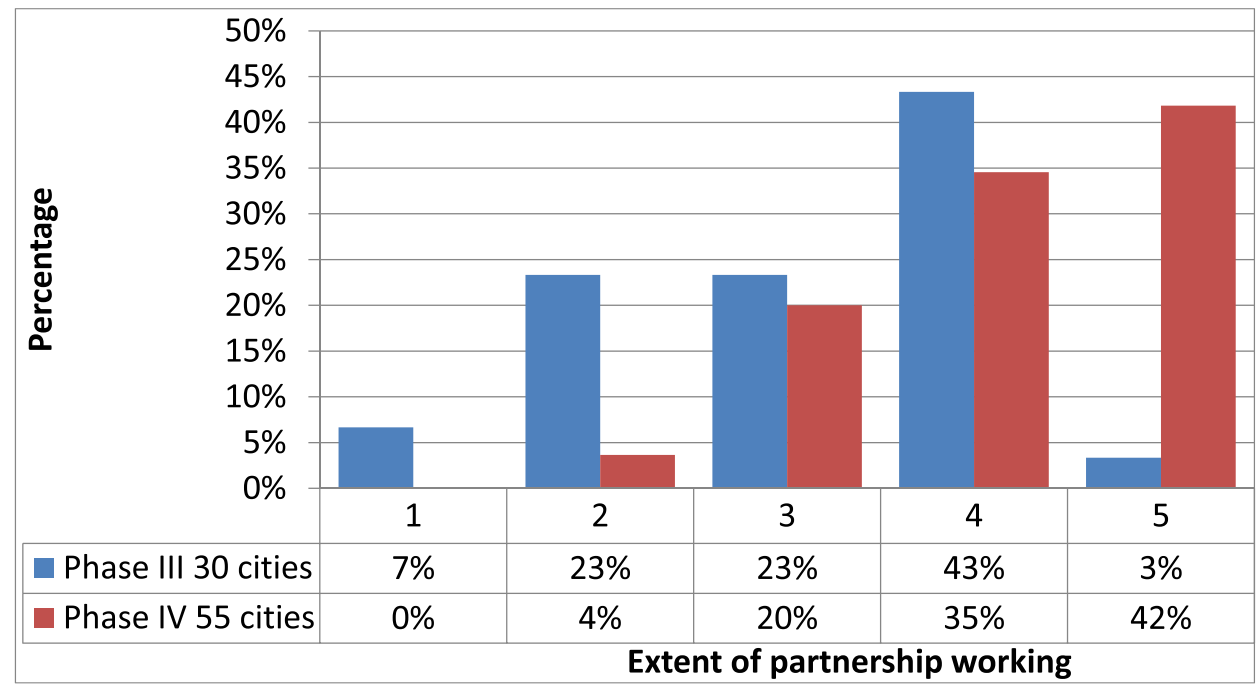

Extent of partnership working: 1 = "No contact"; 2 = "Share information"; 3 = "Agreement to collaborate"; 4 = Collaboration has resulted in agreed plans/strategies; 5 = "implementation of agreed plans, projects or programmes".

FIGURE 5. Partnerships with the urban planning sector changes between phase III and phase IV.

Question 2.3: Please summarize the terms of reference of your main/formal Healthy City partnership, indicating whether it has changed since phase III?

Fifty-four cities responded. Formal Healthy Cities partnerships may include objectives of improving the health of the city, increasing awareness of the benefits of a healthy lifestyle, the application of WHO principles, strategic leadership, promotion of sustainable development and the reduction of health inequalities. For most cities involved in both phases III and IV, there appears to have been no

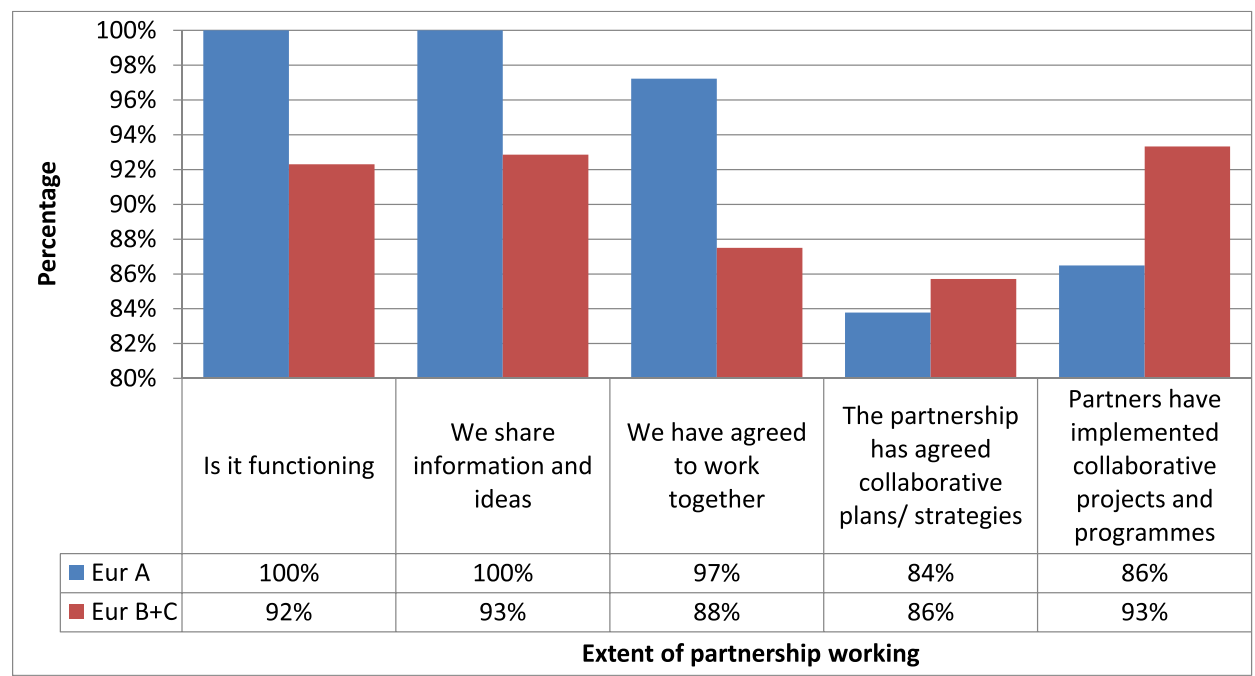

FIGURE 6. Extent of partnership working in the formal partnership "EUR A" countries compared with "EUR B+C" countries. 
significant change in terms of reference, suggesting little change in context or substance of the local project. There were some cyclical political and administrative changes in some cities, and in others, the focus moved onto phase IV themes such as 'healthy aging' and 'healthy urban planning'.

Question 2.4: Does your main/formal partnership focus more on (1) planning and supervising collaborative projects, (2) longer term strategic planning across the city or (3) both equally?

Fifty-four cities responded. This question gauges the maturity of partnerships via their role in strategic planning and city governance. The options provided recognize that, in the earlier stages of collaborative working, initiatives tend to revolve around smaller scale projects. It takes longer to build the trust and skills to work together on integrative strategic planning. Some long-standing partnerships now focus solely on strategic planning $(19 \%)$, leaving the design and implementation of operational plans and collaborative projects to others. Twenty-two per cent of cities focused more on supervising collaborative projects. However, the majority $(59 \%)$ of 54 cities reported that their formal partnership had an equal balance between supervising collaborative projects and longer term strategic planning across the city. There was no substantial difference between EUR A and EUR B+C cities.

\section{Question 2.5: Please summarize engagement with any other partnerships to achieve phase IV objectives.}

Fifty-four cities responded. A Healthy City partnership could position itself as the overarching partnership body which integrates and coordinates all other work streams and partnership activities in a municipality. It could thus influence the use of all available resources in the city towards an overarching aim of improving health and well-being and reducing inequities. However, in the real world, there are other partnerships at municipality level which either perform, or compete to perform, this overarching role. Also, there are often thematic partnerships which bring together key stakeholders in domains such as health and social services, environmental protection, sustainable development and urban planning.

The challenge then is for a Healthy City partnership to position itself effectively in relation to other integrative partnerships and to liaise effectively and influentially with the partnerships that focus on specific thematic areas. The price of failure might, for example, leave a Healthy City partnership only influencing health promotion activities within the health sector. The answers to this question indicated that overall, Healthy City partnerships had engaged with a large variety of other partnerships. However, the answers did not indicate the relative strength of that engagement nor the relative strength and direction of influence resulting from that engagement. It was not possible to assess the extent to which a Healthy City partnership was functioning as an overarching and integrative partnership.

Question 2.6: Identify two facilitative factors and two obstacles that influenced the outcomes of your intersectoral work.

Fifty-seven cities responded.

\section{Facilitative Factors}

Political Support Facilitative factors reported for phase IV are similar to those for phase III. Since accreditation of a WHO Healthy City requires formal submission of 
a council's commitment, municipal support is necessary. However, it was also clear that explicit political support was essential to the success of the partnership. Commitment was required of many, and preferably all, key partners, not just from within the municipality. A change of political leadership can adversely impact on commitment, but this seems to be a rare event. Commitment seems to be maintained, indicating that the initiative transcends political perspectives.

The enormous and unanimous political drive to make this project succeed Leadership and commitment from key individuals

A strong political commitment from all political parties

Well-Organized and Placed Healthy City Office/Team The physical and organizational location of the Healthy City reflects political commitment to the initiative and the status or influence accorded to the team. If the secretariat is itself the fruit of the partnership commitment, then this seems to add to the value of the Healthy City office and team. If the team membership reflects the integration of a number of agencies, then this also increases its influence and effectiveness. The calibre of the team is also an important influence.

An integrated office which often gave the possibility to share and complement competencies, resources and instruments and consequently to provide final added value

An organizational positioning of the Healthy City Project at the strategic level within the City Council

Presentability of the interdepartmental team, including the most skilled experts, leaders or branches and departments

The existence of the Joint Health Unit...based with the City Council, but largely funded by the health service...is seen by both the health service and the council as being crucial to delivering both better relationships between the two and core health improvement initiatives.

WHO Support and 'Branding' WHO initiated the Healthy Cities network to facilitate intersectoral collaboration at the local government level and to share learning between member cities. It is interesting to explore how cities choose to reference their participation in the network within the local partnership-and, in particular, how they use the WHO branding. In the phase III evaluation, cities were divided into two broad groups: first were cities that actively used WHO branding to increase the credibility of and enthusiasm towards their initiatives and second were cities that, whilst using WHO as a source of expertise and support, preferred to reflect and credit the contribution of local partner agencies in initiatives. Here, the WHO branding was rarely used or used discreetly. These two approaches were maintained in phase IV.

The WHO label, or better, the WHO framework has always been a help for our intersectoral work.

The WHO badge with a neutral focus

\section{Obstacles}

Four of the six main obstacles reported relate to organization and funding: (1) constant changes in structures and personnel leading to 'planning blight'; 'limited' 
(2) resources restricting the (3) contribution of healthy cities staff, especially when 'intersectoral work is done in addition to everyday duties'; and (4) a requirement to translate WHO documents. There may also be (5) poor understanding of the value of intersectoral and partnership working and (6) organizational barriers to its realization.

Low level of information awareness of few sectors about an impact and connections of their activities on health, e.g. economic sector Organizational structures of the local authorities are outdated. They can be defined as hierarchical machine bureaucracy.

Frequently, Healthy Cities' teams are obliged to re-emphasise the value of partnerships in addressing the more intractable problems in the city and explain how initiatives in other sectors can bring important health benefits.

Question 2.7: What were the lessons you learnt in relation to building and sustaining health partnerships and intersectoral work?

Fifty-four cities responded. Lessons were closely allied with the facilitative factors and obstacles revealed in response to the previous question. The quotations below reflect the balance of opinion.

1. The value of intersectoral collaboration

We thought that we knew, but we really learned that it's impossible (to) improve the people health without intersectoral work. Intersectoral work enhances the final result.

2. The particular difficulty of intersectoral working

We have to accept that partnerships and intersectorial relations are, according to our experience, one of the most complicated missions to lead the project as it must be. At the occasion of some annual business meetings, a lot of coordinators have expressed the great difficulty of this task in their country which is considered a real challenge.

3. The need for change in organizational structure to achieve this.

In terms of intersectoral work...we have learnt that it is difficult to implement a global strategic focus...in all decisions and activities in all sectors without a focus on the structural mechanisms of changing the procedures of strategic decision making in each sector.

4. Political support and leadership

Gain commitment from Chief Executive. The importance of top politician's commitment. Endurance, tenacity, leadership and optimism.

\section{Good communication}

We used many methods...regular information distribution through information email system, organizing of annual festive meetings reflecting the most important activities of the Healthy City, providing help for getting grants for health activities.... 
6. The value of mutual support from different sectors

At the very beginning, some of the technicians or politicians...could not see why they had to cooperate with "Health and Social" sector and in the first meetings, they were suspicious. But when they realized...we have to work in a balance for all areas, and started the cooperation to make common plans that involved and facilitate different sectors, became not only helpful, but supported the project very dynamic when we were faced with troubles. This that was amazing, was that when some of them had some troubles, (they) asked for help from the Healthy City team of experts.

\section{Time-and a longer term perspective}

Investing time to ensure all partners can identify the role they play in the project. Partnership processes are often slow and require significant time to maintain. The intersectoral action needs time to be develop and be convincing about its plus value. Collaborating and networking means a major initial effort but produces, as time goes by, better results.

\section{Good project and people management}

The importance of defining objectives, indicators to evaluate them and, most of all, the designation of competencies to achieve them. The importance of negotiating objectives and establishing goals with reasonably high standards. The importance of identifying top-level technicians who are highly motivated to perform the work they have to perform; The importance of a proper understanding of the needs of the institutions and of responding to these needs.

\section{Question 2.8: Would the partnerships and intersectoral collaborations you established under the healthy cities umbrella/logo continue if you stopped being a member of the WHO network?}

Fifty-six cities responded. Eighty-two per cent of responding cities reported that partnership working and intersectoral collaboration would continue if their city stopped being a member of the WHO network, $14 \%$ were uncertain, and only $4 \%$ believed partnership working would stop if they left the network. Many cited their experience of partnership and intersectoral collaboration, developed through being a member of the WHO network, had persuaded local government of the benefits of this way of working. This was the basis for its continuation irrespective of future WHO network membership.

...new work modalities were created and adopted. This partnership is now understood as the most effective way of thinking projects, assigning resources to its conduction and develop the core work itself. These collaborations are now set within well established organizational structures and management systems and it is not related to continuous membership of the WHO network.

Nevertheless, many cities considered that the intensity of partnership working and the ease with which partnerships were developed and maintained was partly achieved through membership of the WHO network: if their city was not a member, partnership working would diminish:

...it will be more difficult without WHO's help. But WHO network membership is important for leadership, inspiration and motivation of politicians and 
decision-makers to keep Healthy City Project running. Being part of the WHO gives strength and credibility to this approach. ...the intensity and authority would be weaker, if we could not lean on the Healthy Cities core themes and WHO expertise. Indeed the prestige of the WHO logo is so important that all agencies are happy to link to the Healthy Cities logo...so the fact of having the WHO...identity makes easier to attract partners and collaboration on health issues. Belonging to the...network provides us with significant public status and recognition, which we consider essential to exerting influence in some sectors in relation to decisions impacting health.

Without membership: ...the leverage of the WHO to engage politicians and senior members of agencies and organisations would be gone. The WHO network represents for politicians and decision-makers a guide as well as a guarantee of the value and importance they are attributing to health in the implementation of their policies at a local level.

\section{DISCUSSION}

Though assessment of the scope and effectiveness of partnerships is notoriously difficult, ${ }^{17}$ this pragmatic evaluation rests on a number of assumptions made by WHO and supported by the evidence and conceptual propositions summarised in the Introduction. First, population health is improved by the interventions of many sectors. Second, different agencies and tiers of government have competencies for each of these sectors. Third, local governments have a convening power to coordinate sector interventions at a city local level. Fourth, a strategic rather than project-based approach is required to develop healthy public policy as, fifth, a framework for healthy settings and investment programmes and, sixth, a prelude to health improvement at a city level. ${ }^{21}$ This conceptual framework is neither a free market nor statist, relying instead on theoretical propositions underpinning the Health in all Policies framework ${ }^{22}$ adopted by the European Union as appropriate for a network society. ${ }^{23}$

However, there are two main weaknesses in this evaluation. First, a common lacuna ${ }^{24}$; outcomes were not assessed because of resource constraints and methodological difficulties in ascribing health gain to certain types of policy and programme. $^{25}$ Therefore, it was not possible to assess the impact of strategic partnerships either on healthy public policy or population health. Second, though the evaluation centrally addresses how to translate the rhetoric of partnership working into practical reality, ${ }^{26}$ it was difficult to critically assess effectiveness. Ordinal scales elicited cities' own assessments of levels of engagement and achievement, but their relatively high scores may mask a more modest reality. Future evaluations should be guided by a more rigorous programme logic or theory ${ }^{27}$ after reviewing the range of formal assessment tools. ${ }^{28-30}$

Predictably, our review shows that the health sector and allied social services participate most in Healthy Cities' partnerships. The challenge is to reach out to other departments and indeed beyond the public sector. In order to address in joined-up ways all the social determinants of health, we require, in the rhetoric of the twenty-first century, Health in All Policies. ${ }^{12}$ Our findings show the potential of such HiAPs and suggest that partnering may be easier with some sectors and actors, and certain conditions may be put in place to create and sustain partnerships. We would postulate that some of the possible partners in Healthy City actions are yet 
unaware of the potential gain of engaging in the partnership, either because they have not acknowledged the health component of their work or the assets that can be derived from working with a Healthy City vision. This is entirely consistent with the conceptual framework compiled in the Introduction.

Healthy urban planning illustrates the point. Partnerships rated at the highest level increased from $3 \%$ in phase III to $42 \%$, clearly stimulated by this being a core theme in phase IV of the WHO-EHCN and indicating that WHO's developmental guidance and networking in this novel domain had an impact. Cities report that WHO branding and opportunities to network with other cities contributed to their success in a 'learning' network.

Education and the voluntary sector are common partners in Healthy Cities, but we see a surprising underrepresentation of the Transport and Environment sectors in urban health partnerships even though these had constituted the key theme in phase III of the network; a number of transnational and global initiatives might have maintained a strong impetus for continuing efforts in this domain. ${ }^{31}$ This may well be explained as a function of differing organisational cultures.

The WHO Commission on Social Determinants of Health ${ }^{32}$ demonstrated the pivotal connection between wealth and health. However, Healthy Cities seem less engaged with the economic sector and joint initiatives with the private sector are poorly developed. This is consistent with other studies, for example in Victoria (Australia) where state government requires local governments to plan for health in four so-called environments, including the economic environment. Virtually every local government there reports conceptual challenges in operationally connecting health and wealth. ${ }^{33,34}$

Generally, both the quality and quantity of partnerships increased between phases III and IV. This suggests that newly designated Healthy Cities have the capacity to adopt innovative approaches relatively quickly. Newly designated cities are well supported by veterans in the network, and the forums through which experiences and information are exchanged are having an impact on performance. Clearly, transparent communications and management practices would further enhance these positive patterns.

The data, however, also show that partnership development, implementation and sustainability need long-term perspectives and continued commitment: $16 \%$ of cities reported that implementation of collaborative projects or programmes remained difficult, and those located in the EUR $\mathrm{B}+\mathrm{C}$ countries reported more development difficulties than others. However, once developed, these same cities reported that implementation was progressing steadily. Such patterns might be attributed to prevailing governance structures in EUR $\mathrm{B}+\mathrm{C}$ areas, where resistance to change and innovation may be dominant, but once overcome, new processes are easily made routine. ${ }^{35}$

Although partnerships have increased in quality and quantity between phases III and IV (and some sectors are more strongly represented than others), there has been very little change in their core terms of reference. Three in four cities claim a strategic planning priority, suggesting that Healthy City partnerships aspire to overcome short-term projectism. ${ }^{36}$ This is also reflected in cities' confidence in continuing their partnerships should they lose WHO Healthy City designation.

\section{CONCLUSION}

Partnerships remain a key and successful component of Healthy City development. The core principles, purpose and intellectual guidance for Healthy City initiatives 
were found by partnerships to remain valid and fit for purpose. Partnerships encompass more sectors than in previous phases and achieve greater degrees of collaborative planning and implementation. This is apparent both for longestablished phase III cities and newcomers to phase IV. The network, and in particular the WHO brand, is well regarded and is seen as a powerful encouragement for political and organisational engagement and a source of support and technical expertise. The specific use of themes in phase IV-and the additional technical support and networking that accompanied this-was particularly successful in encouraging intersectoral collaboration in the field of healthy urban planning.

For further successful development of partnerships in Healthy Cities, and based on the material presented here, a more rigorous analytical framework and theoryinformed approach to reviewing partnership and collaboration parameters should be applied in the future. In addition, an increased emphasis on partnerships and collaborations at the interface between health and wealth is warranted.

\section{REFERENCES}

1. Milio N. Promoting Health through Public Policy. Philadelphia, Pennsylvania: Davis; 1981.

2. Hancock T, Duhl L. Healthy Cities: Promoting Health in the Urban Context. Healthy Cities Paper \#1. Copenhagen: Copenhagen, Denmark: WHO Regional Office for Europe; 1986.

3. Tsouros AD ed. World Health Organization Healthy Cities Project: A Project Becomes a Movement; Review of Progress 1987-1990. Copenhagen, Denmark: WHO Regional Office for Europe; 1990.

4. WHO Regional Office for Europe. Phase V (2009-2013) of the WHO European Healthy Cities Network: Goals and Requirements. Copenhagen, Denmark: WHO; 2009.

5. Dowling B, Powell M, Glendinning C. Conceptualising successful partnerships. Health Soc Care Community. 2004; 12: 309-317.

6. Smith KE, Bambra C, Joyce KE, Perkins N, Hunter DJ, Blenkinsopp EA. Partners in health? A systematic review of the impact of organizational partnerships on public health outcomes in England between 1997-2008. J Publ Health. 2009; 31(2): 210-221.

7. Draper R, Curtice L, Hopper L, Gorman M. WHO Healthy Cities Project: Review of the First Five Years (1987-1992): A Working Tool and Reference Framework for Evaluating the Project. Copenhagen, Denmark: WHO Regional Office for Europe (EUR/ICP/HSC 644); 1993.

8. The Partnerships Analysis Tool: For Partners in Health Promotion. Melbourne, Australia: VicHealth. 2004. Available from http://www.vichealth.vic.gov.au/en/Publications/Mentalhealth-promotion/Partnerships-Analysis-Tool.aspx. Accessed December 12, 2011.

9. Hudson B, Hardy B. What is a 'successful' partnership and how can it be measured? In: Glendinning C, Powell M, Rummery K, eds. Partnerships, New Labour and the Governance of Welfare. Bristol, England: Policy Press; 2002: 51-65.

10. Jones J, Barry MM. Exploring the relationship between synergy and partnership functioning factors in health promotion partnerships. Health Promot Int. 2011; 26(4): 408-420.

11. Sabatier P, Jenkins-Smith H (eds). Policy Change and Learning: An Advocacy Coalition Approach. Boulder, CO: Westview Press; 1993.

12. Goumans MJBM. Innovations in a Fuzzy Domain: Healthy Cities and (Health) Policy Development in the Netherlands and the United Kingdom. Maastricht, England: Maastricht University; 1998.

13. Hoeijmakers M, de Leeuw E, Kenis P, de Vries NK. Local health policy development processes in the Netherlands: an expanded toolbox for health promotion. Health Promot Int. 2007; 22(2): 112-121. doi:10.1093/heapro/dam009. 
14. de Leeuw E. Ottawa Charter. Oxford Bibliographies. 2011. Available at: www.oxfordbibliographiesonline.com/display/id/obo-9780199756797-0070. doi:10.1093/obo/ 9780199756797-0070. Accessed on 14 March 2011.

15. Hueben F, de Leeuw E. Intersectorale samenwerking: de theorie en de praktijk. H. 5 [Intersectoral collaboration: the theory and the practice. Ch.5]. In: Leeuw E. de, ed. Gezonde Steden. Lokale gezondheidsbevordering in Theorie, Politiek en Praktijk [Healthy Cities. Local Health Promotion in Theory, Politics, and Practice]. Assen/ Maastricht: Van Gorcum; 1991:87-108.

16. Gray B. Conditions facilitating interorganizational collaboration. Hum Relat. 1985; 38 (10): 911-936.

17. El Ansari WE, Phillips CE, Hammick M. Collaboration and partnerships: developing the evidence base. Health Soc Care Community. 2001; 9(4): 215-227.

18. Zahner SJ. Local public health system partnerships. Publ Health Rep. 2005; 120: 76-82.

19. Skok JE. Policy issue networks and the public policy cycle: a structural-functional framework for public administration. Publ Admin Rev. 1995; 55(4): 325-332.

20. Green G, Price C, Lipp A, Priestly R. Partnership structures in the WHO European Healthy Cities project. Heal Promot Int. 2009; 24(S1): i37-i44.

21. Tsouros AD. City leadership for health and sustainable development: the World Health Organization European Healthy Cities Network. Heal Promot Int. 2009; 24(Sl): i4-i10.

22. Ståhl T, Wismar M, Ollila E, Lahtinen E, Leppo K. Health in All Policies: Prospects and Potentials. Ministry of Social Affairs. Helsinki, Finland: European Observatory on Health Systems and Policies, Brussels, Belgium: 2006.

23. Castells M. The Rise of the Network Society. Oxford: Blackwell; 1996.

24. Smith KE, Bambra C, Joyce KE, Perkins N, Hunter DJ, Benkinsopp EA. Partners in Health? A systematic review of the impact of organizational partnerships on public health outcomes in England between 1997-2008. J Publ Health. 2009; 31(2): 210-221.

25. De Leeuw. Do healthy cities work? A logic of method for assessing impact and outcome of healthy cities. J Urban Health. 2011. doi:10.1007/s11524-011-9617-y.

26. Glendinning C, Clarke J. Old wine, new bottles? Prospects for NHS/local authority partnerships under New Labour. Paper prepared for the ESRC seminar on The Third Way in Public Services-Partnership, University of York, 11 April; 2000.

27. Birckmayer JD, Weiss CH. Theory-based evaluation in practice: what do we learn? Eval Rev. 2000; 24: 407-431.

28. Haliday J, Asthana SNM, Richardson S. Evaluating partnership: the role of formal assessment tools. Evaluation. 2004; 10: 285-303.

29. Hardy B, Hudson BA, Waddington E. What Makes a Good Partnership? A Partnership Assessment Tool. Leeds: Nuffield Institute for Health; 2000.

30. Asthana S, Richardson S, Halliday J. Partnership working in public policy provision: a framework for evaluation. Soc Pol Admin. 2002; 36(7): 780-795.

31. Bentley M. Healthy cities, local environmental action and climate change. Heal Promot Int. 2007; 22(4): 246-253.

32. WHO Commission on Social Determinants of Health. Closing the Gap in a Generation: Equity through Action on the Social Determinants of Health. Geneva, Switzerland: World Health Organization; 2008.

33. Department of Human Services. Environments for Health, Promoting Health and Wellbeing through the Built, Social, Economic and Natural Environments, Municipal Public Health Planning Framework. DHS, Victoria, Melbourne; 2001.

34. de Leeuw E, Butterworth I, Garrard J, Palermo J, Godbold T, Tacticos T. Evaluation of the Environments for Health Framework, pp. 1-68. Deakin University and The University of Melbourne, Australia; 2006.

35. Stark D, Bruszt E. Postsocialist Pathways: Transforming Politics and Property in East Central Europe. Cambridge, England: Cambridge University Press; 1998.

36. Goumans M, Springett J. From projects to policy: healthy cities as a mechanism for policy change for health? Heal Promot Int. 1997; 12(4): 311-321. 